\title{
Marco Rosa
}

MD, DDS, D. Orthod - Itália

- Doutor em Ortodontia.

- Especialista em Dentística.

- Membro Ativo da Angle Orthodontic Society.

- Diplomado pelo Board Europeu de Ortodontia e pelo Board Italiano de Ortodontia.

- Professor na Universidade Insubria Varese - Itália.

- Prática privada em Trento - Itália.

- Diversos artigos publicados na Europa, EUA e Brasil.

- Ministrou cursos e palestras no mundo inteiro sobre o tratamento interdisciplinar, envolvendo a

Ortodontia e o tratamento precoce.

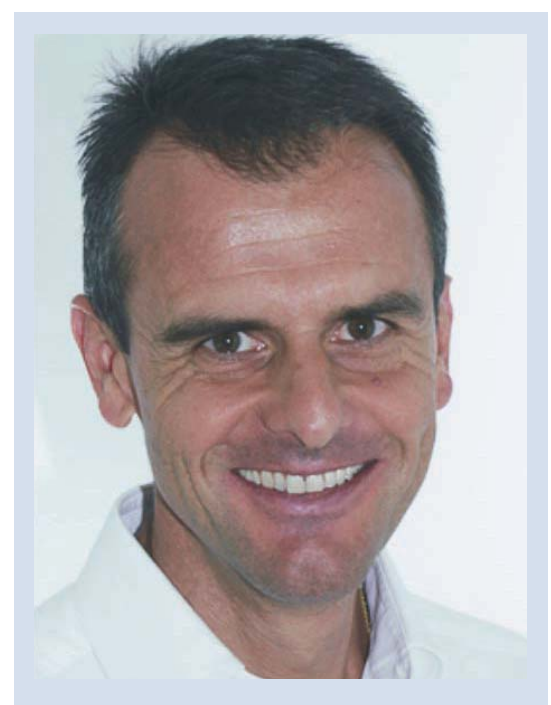

No início dessa década, tive contato com informações clínicas preciosas sobre o fechamento de espaço em casos com agenesia dos incisivos laterais superiores, através de duas fontes básicas. A primeira foi um artigo ${ }^{14}$ do JCO (2001), cuja tradução foi publicada na Revista Clínica de Ortodontia Dental Press ${ }^{12}$, em 2002. A segunda, uma excelente apresentação no Congresso Americano de Ortodontia (AAO), no ano seguinte. A apresentação do Dr. Marco Rosa, corroborada pelo artigo publicado em parceria com seu ex-professor, ninguém menos que o Dr. Björn Zachrisson, deixava a mensagem de que é possível conseguir o fechamento de espaços substituindo os laterais por caninos, com resultados belíssimos.

Em 2007, no Congresso da AAO, em Seattle, a dupla Rosa e Zachrisson proporcionou um show aos olhos dos ortodontistas presentes, muitos brasileiros. Os autores mostraram novos procedimentos, descritos nessa entrevista, que melhorariam, ainda mais, os resultados nesses casos. A conseqüência dessa apresentação ímpar foi o surgimento de vários convites para o Dr. Rosa ministrar cursos. Assim, ele estará no Brasil em agosto, nas cidades de Fortaleza e Belém, e em outubro, na cidade do Rio de Janeiro - participando das comemorações do 50 aniversário de criação do Curso de Ortodontia da UFRJ. Simplesmente imperdível...

O Prof. Rosa é italiano e vive em Trento, na região dos Alpes. Casado com uma farmacêutica, Sabrina, é pai de duas meninas, Eugenia e Ludovica. Além de adorar trabalhar e viajar com a família, é fã de esportes e instrutor de esqui. Acima de tudo, considera-se um homem de muita sorte (eu diria abençoado), pois tem tido encontros memoráveis na vida. Além da belíssima família, no campo profissional o Dr. Rosa teve como instrutor o Dr. Zachrisson. Se não bastasse, como instrutor de esqui, teve como aprendiz o Papa João Paulo II. Alguém que tem algo a ensinar ao nosso saudoso Papa, tem, com certeza, muito a nos ensinar, como pode ser visto nesta entrevista. Sorte de todos nós...

David Normando 
Os procedimentos estéticos são de grande importância na Odontologia. Quando o Sr. indica o fechamento dos espaços para substituir os incisivos laterais em casos de agenesia? Lincoln Nojima

Quando o paciente com agenesia de incisivos laterais superiores apresenta sorriso gengival ou mostra apenas os tecidos moles periodontais, ao falar ou sorrir, é sempre melhor evitar a solução com implantes. Neste caso, o fechamento do espaço deve ser realizado, especialmente quando a diferença de tamanho entre o canino e o primeiro pré-molar é pequena.

$\mathrm{Na}$ verdade, em caso de fechamento do espaço, um tratamento ortodôntico cuidadosamente detalhado, seguido de procedimentos não-invasivos da Dentística Estética ${ }^{12,13,14}$, pode proporcionar não somente a finalização ortodôntica, mas, também, um bom prognóstico em longo prazo (Fig. 1).

Por outro lado, o prognóstico de uma restauração com implante na área mais visível da boca é imprevisível em longo prazo, devido à possibilidade de problemas periodontais ao redor do implante e, acima de tudo, pela erupção contínua dos dentes adjacentes, com conseqüente infra-oclusão da restauração com implante ${ }^{1,2,3,15}$ (Fig. 2).

Durante o congresso da AAO, em Seattle (2007), o Sr. apresentou excelentes casos de agenesias de incisivos laterais tratados com mesialização dos caninos e pré-molares, seguida de reanatomizações dentárias com compósitos, e outros mediante a abertura do espaço para reabilitação com implantes. Nestes anos de experiência, qual seu parecer sobre os benefícios de cada método, e quais problemas tem observado ao controlar estes casos em longo prazo, tanto sob a óptica restauradora quanto periodontal? Adilson Ramos

Em caso de reabertura de espaço para restauração com um implante único, a principal vantagem é a possibilidade de obter uma oclusão protegida pelo canino, na qual apenas uma restauração foi necessária para reabilitar o dente ausente. Ao final do tratamento, a sobressaliência e sobremordida serão normais.

Por outro lado, a alternativa de fechamento do espaço significa um compromisso na oclusão, que pode
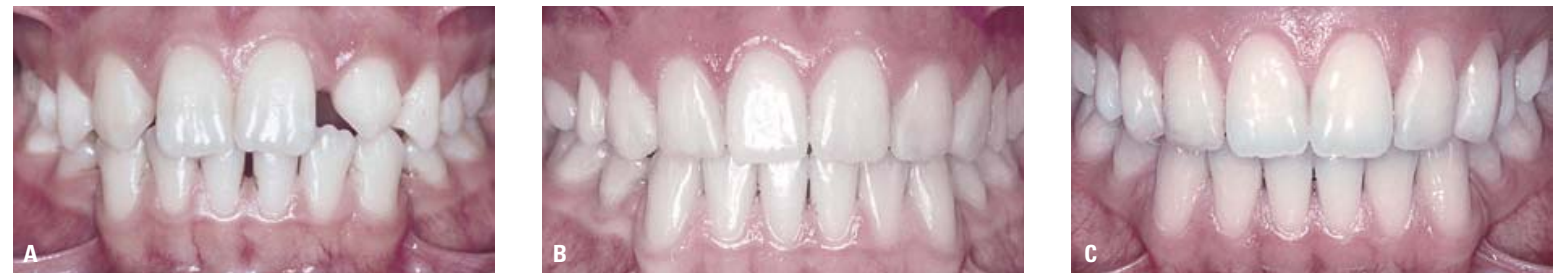

FIGURA 1 - Caso AZ: antes do fechamento do espaço (A), ao final do tratamento, com dentes reanatomizados (B) e 10 anos após o tratamento (C).
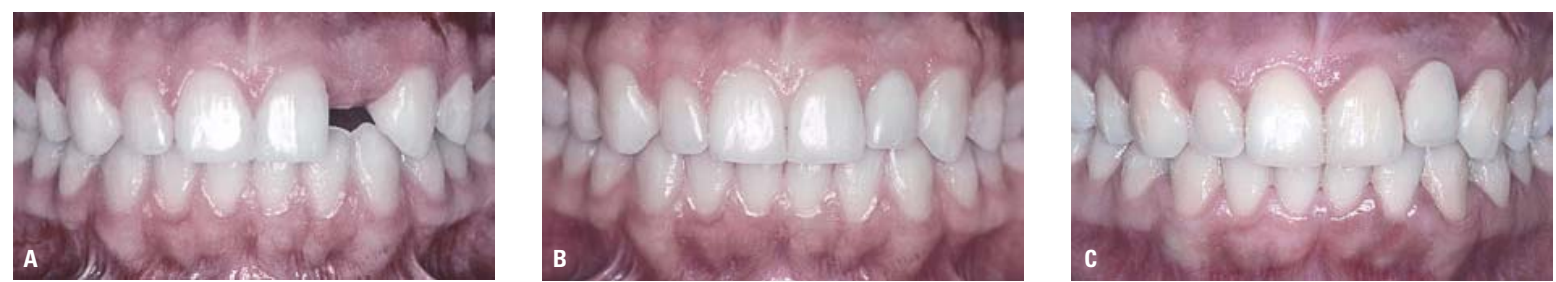

FIGURA 2 - Obtenção de espaço para implante em indivíduo do gênero feminino, 20 anos de idade (A); após o final do tratamento com restauração sobre implante (B) e apenas 5 anos após a colocação do implante observa-se infra-oclusão da coroa de porcelana (C). 
ser adequadamente resolvido através de desgaste dos caninos e duas restaurações nos caninos e primeiros pré-molares. Entretanto, em alguns pacientes é necessário aceitar uma sobressaliência e sobremordida não-ideais, devido ao índice de discrepância de Bolton. Algumas vezes, é necessário planejar a restauração, também dos incisivos centrais, com a finalidade de obter um equilibrio ideal dente a dente, dentes com lábios e dentes com face (Fig. 3).

A perspectiva em longo prazo é o aspecto mais crucial a ser considerado quando da decisão pelos implantes. Nós, ainda, não sabemos como os implantes ósseo-integrados se comportarão em longo prazo, mesmo que poucas evidências científicas e muitos relatos clínicos revelem problemas poucos anos após a colocação dos implantes: recessão gengival com exposição da raiz, coloração azulada da gengiva e infra-oclusão do implante, mesmo quan- do este é colocado após cessado o crescimento.

Por outro lado, os principais problemas em longo prazo para os pacientes com fechamento de espaço são muito menos relevantes do ponto de vista clínico:

- como existe tendência de reabertura de espaços, uma finalização detalhada nas relações oclusais e contenção de longo prazo são necessárias;

- em função da tendência de recessão gengival nos caninos, agora laterais, devido à raiz mais espessa e ao fino tecido periodontal na face vestibular, é importante inserir um torque palatino na raiz do canino, durante a finalização ortodôntica;

- como as restaurações com compósitos sofrem ação do tempo, necessitam de manutenção regular, embora simples. As facetas laminadas (veneers) coladas em esmalte apresentam as melhores soluções em longo prazo (Fig. 3C, D).
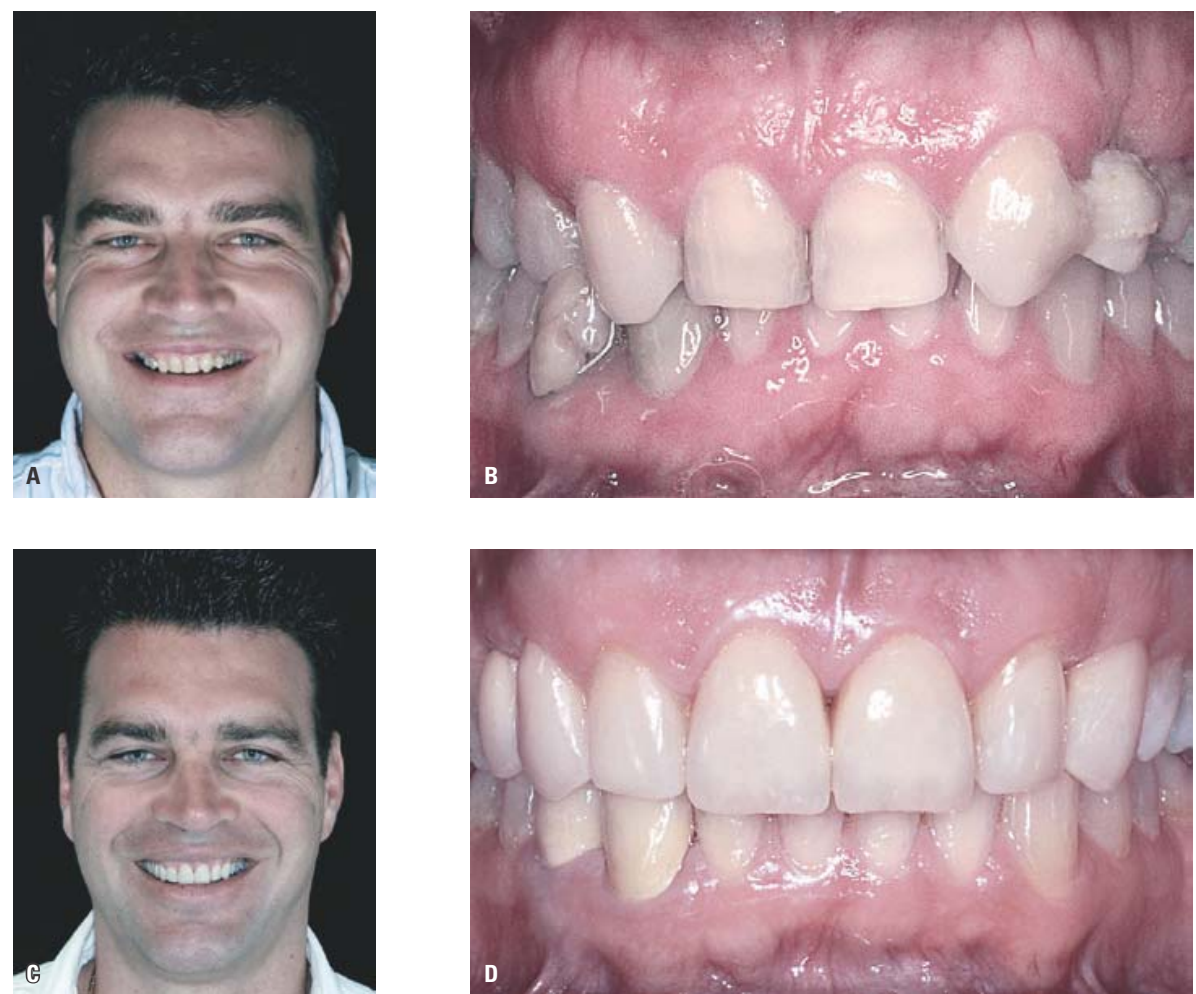

FIGURA 3 - Caso AT: início (A, B) e final (C, D) do tratamento. Os laterais superiores ausentes foram substituídos pelos caninos e seis facetas laminadas de porcelana foram coladas nos incisivos centrais, nos caninos e nos primeiros pré-molares superiores, para se obter oclusão proporcional e estética ideal. 
O problema em tratar casos com agenesia dos incisivos laterais superiores envolve a decisão entre fechar espaço ou reabrir espaço. Considerando tudo que o Sr. tenha lido ou pesquisado ultimamente, houve alguma informação que tenha lhe forçado a mudar sua prática clínica? Marcos Alan Bittencourt

Nas últimas décadas, a introdução dos implantes ósseo-integrados reduziu a popularidade das alternativas de fechamento de espaço. Evidentemente, eu também comecei a reabrir os espaços, mas, imediatamente, ficou evidente para mim que "a solução" na área do sorriso não era os implantes. As principais razões para isso foram:

- algumas vezes, era muito difícil, mesmo para dentistas habilidosos, obter um resultado final que parecesse natural;

- os adolescentes tinham que esperar um tempo longo, até o final do tratamento (que é difícil definir), para receber a reabilitação com implantes. Esses pacientes jovens tinham que "sobreviver" com restaurações temporárias insatisfatórias, por muitos anos, tomando cuidado com algumas quebras ou falhas. Seguramente, eles prefeririam ter o tratamento todo finalizado imediatamente após a terapia ortodôntica;

- a estabilidade pobre, mesmo em adultos, após o final do crescimento, especialmente devido aos comportamentos atípicos daqueles "corpos estranhos", quando comparada às alterações normais e contínuas dos dentes adjacentes naturais (Fig. 2B, C).

Por outro lado, eu não esqueci os resultados finais satisfatórios obtidos no passado por meio do fechamento de espaço. Aqueles resultados poderiam, ainda, ter sido melhorados por uma finalização ortodôntica detalhada, apoiada nos novos procedimentos introduzidos na Odontologia:

- intrusão dos primeiros pré-molares, agora caninos, e extrusão dos caninos, agora laterais, com a finalidade de se alcançar um perfil periodontal ideal;

- torque palatino de raiz no canino, agora lateral, com a finalidade de proporcionar uma espessura de osso alveolar adequada e prevenir recessões no novo incisivo lateral;

- clareação no canino, agora lateral, preservando sua vitalidade;

- utilização de compósitos híbridos, que combinam resistência e estética, para restaurações dos dentes anteriores;

- utilização de facetas laminadas (venners) de porcelana colada em esmalte, uma alternativa para casos esteticamente mais complexos.

Essas são as razões pelas quais eu não só fecho os espaços, mas também comecei a trabalhar no atrativo caminho de melhorar esse tipo de tratamento.

$\mathrm{Na}$ verdade, naquele período, apenas resultados finais clínicos excelentes poderiam mudar a opinião comum de que "implantes são melhores". Atualmente, a primeira evidência científica dos problemas inerentes aos implantes, na região anterior, está disponível e será mais fácil propor, novamente, o fechamento de espaço como uma alternativa valiosa. Eu também acredito que, em caso de reabertura do espaço, todas as restaurações protéticas tradicionais usadas na era pré-implante, especialmente as próteses de cantilever, voltarão a se tornar populares, no paciente com sorriso gengival, como alternativa ao implante.

Uma vantagem evidente do fechamento de espaço é a compatibilidade biológica da dentição natural ao final do tratamento. $\mathrm{O}$ Sr. poderia apontar uma grande vantagem da reabertura de espaço? Marcos Alan Bittencourt

A única vantagem relevante da reabertura de espaço é a possibilidade de obtenção de uma oclusão perfeita, protegida por canino, com sobressaliência e sobremordida ideais. Fechando os espaços, em alguns pacientes, teremos que aceitar uma oclusão compromissada, devido ao índice de discrepância de Bolton.

É importante considerar se a ausência do incisivo lateral é unilateral ou bilateral, na decisão clínica de fechar ou abrir o espaço? David Normando

A ausência assimétrica de um incisivo lateral 
superior é um fator crucial para o planejamento do tratamento, mas não é suficiente para determinar a abertura ou o fechamento do espaço. A relação oclusal, as discrepâncias esqueletais e, principalmente, a quantidade de exposição gengival - assim como o tamanho e a morfologia dos caninos, primeiros pré-molares e incisivos - são fatores fundamentais a serem avaliados.

De qualquer forma, a simetria da exposição final dos seis dentes ântero-superiores é um dos objetivos mais relevantes. Assim, se o plano de tratamento for fechar o espaço, eu indico, também, quase sempre, extrair o incisivo lateral presente, especialmente quando for um dente conóide ou muito pequeno, a fim de criar um perfil periodontal simétrico.

Em alguns relatos recentes, nós podemos verificar que o Sr. lista várias vantagens do fechamento do espaço. Por outro lado, a reabertura de espaço é, geralmente, preferida em pacientes com adequada intercuspidação nos dentes posteriores. Nesses casos, o Sr. considera válido o esforço para movimentar 0 canino mesialmente, com o objetivo de alcançar o melhor resultado estético? Marcos Alan Bittencourt

Em casos de sorriso gengival e quando o paciente mostra a gengiva enquanto fala ou sorri, nós devemos fazer todo o possível para evitar uma solução com implante. Assim, mesmo nos pacientes com uma relação normal de Classe I nos dentes posteriores, nós devemos informar que o fechamento do espaço pode ser a melhor solução, em longo prazo, quando comparado ao implante. Algumas vezes, também com o intuito de tornar o tratamento ortodôntico mais fácil, eu prefiro abrir espaço e colocar um implante único mais posteriormente, no local do segundo pré-molar, fechando os espaços na região anterior.

Em relação à opção pelo fechamento do espaço, é muito comum, em nosso país, ouvirmos os protesistas defenderem que o pré-molar não é o dente ideal para substituir a fisiologia dos caninos, durante os movimentos mandibulares. Qual a sua avaliação clínica e científica deste aspecto? David Normando

Os relatos sobre esse assunto são poucos ${ }^{7} \mathrm{e}$ não há qualquer evidência científica de que os primeiros pré-molares são inadequados para substituir os caninos durante a função. Eu comecei, há mais de 12 anos, construindo a guia canino nos pré-molares movimentados para a área dos caninos. Regularmente, verifico todos os meus pacientes - não apenas clinicamente, mas também com sondagem e radiografias - e, até o momento, não percebi qualquer problema periodontal nos primeiros pré-molares.

Eu espero, no futuro, proporcionar evidência cientifica do que acontece com meus pacientes, tão logo eu tenha dados suficientes que permitam descrever essas conclusões.

A reabsorção óssea na região anterior do alvéolo é um processo fisiológico. $\mathrm{O}$ Sr. acha que esse processo de remodelação exerce alguma influência na decisão entre reabrir ou fechar espaços, em pacientes jovens? David Normando

As alterações biológicas que acontecerão no complexo dentoalveolar, com o envelhecimento, são os fatores mais cruciais a serem considerados no plano de tratamento, especialmente para o paciente jovem, que tem uma longa expectativa de vida.

Uma das muitas razões para considerar o fechamento do espaço como a melhor alternativa é que, independente do que acontecer, com o passar do tempo, na região dentoalveolar, tudo será fisiológico e natural, ou seja, todos os dentes irromperão e sofrerão abrasão, em sincronia, e as alterações periodontais ocorrerão da mesma forma. Além do mais, um bom dentista pode proporcionar restaurações adequadas nos caninos e pré-molares, agora laterais e caninos, sem interferir na saúde e estabilidade dos dentes e dos tecidos periodontais.

Por outro lado, nós sabemos que o implante não acompanhará as alterações naturais dos tecidos periodontais, existindo um risco significativo 
de que o mesmo se torne um corpo estranho em relação aos dentes adjacentes naturais.

Nos casos de protração maxilar, qual o protocolo de contenção que o Sr. utiliza para pacientes tratados precocemente (dentadura mista)? A presença da Classe III esquelética altera seu planejamento quanto a fechar espaços? Adilson Ramos

Em casos de Classe III esquelética, não há evidência de que o tratamento tardio seja mais efetivo em longo prazo, quando comparado ao tratamento eficiente em uma fase precoce. Por outro lado, é difícil estabelecer precocemente os objetivos do tratamento e a expectativa de crescimento. Essa é a principal razão pela qual, após a protração maxilar precoce e sobrecorrigida, eu não faço qualquer contenção até o final da troca dos dentes decíduos. Após o tratamento precoce, minha única preocu- pação é a correção dos hábitos deletérios. A segunda fase do tratamento, se necessária, será iniciada na dentadura permanente completa (melhor ao final do crescimento), após um longo período sem aparelhos e sem preocupação com a cooperação. Nesta época, os objetivos do tratamento serão decididos em conjunto com o paciente.

A presença da Classe III é um importante fator a ser considerado para o planejamento do tratamento em caso de ausência do incisivo lateral superior, em um paciente jovem, mas não é indicação absoluta para a reabertura de espaços. Eu já mostrei que uma alteração significante na inclinação dos incisivos superiores não pode produzir, por si só, melhora evidente ou piora no perfil dos tecidos moles, na Classe III (Fig. 4).

Nas más oclusões de Classe III hipodivergentes, se a cooperação for adequada, é possível fechar os espaços e melhorar a convexidade do
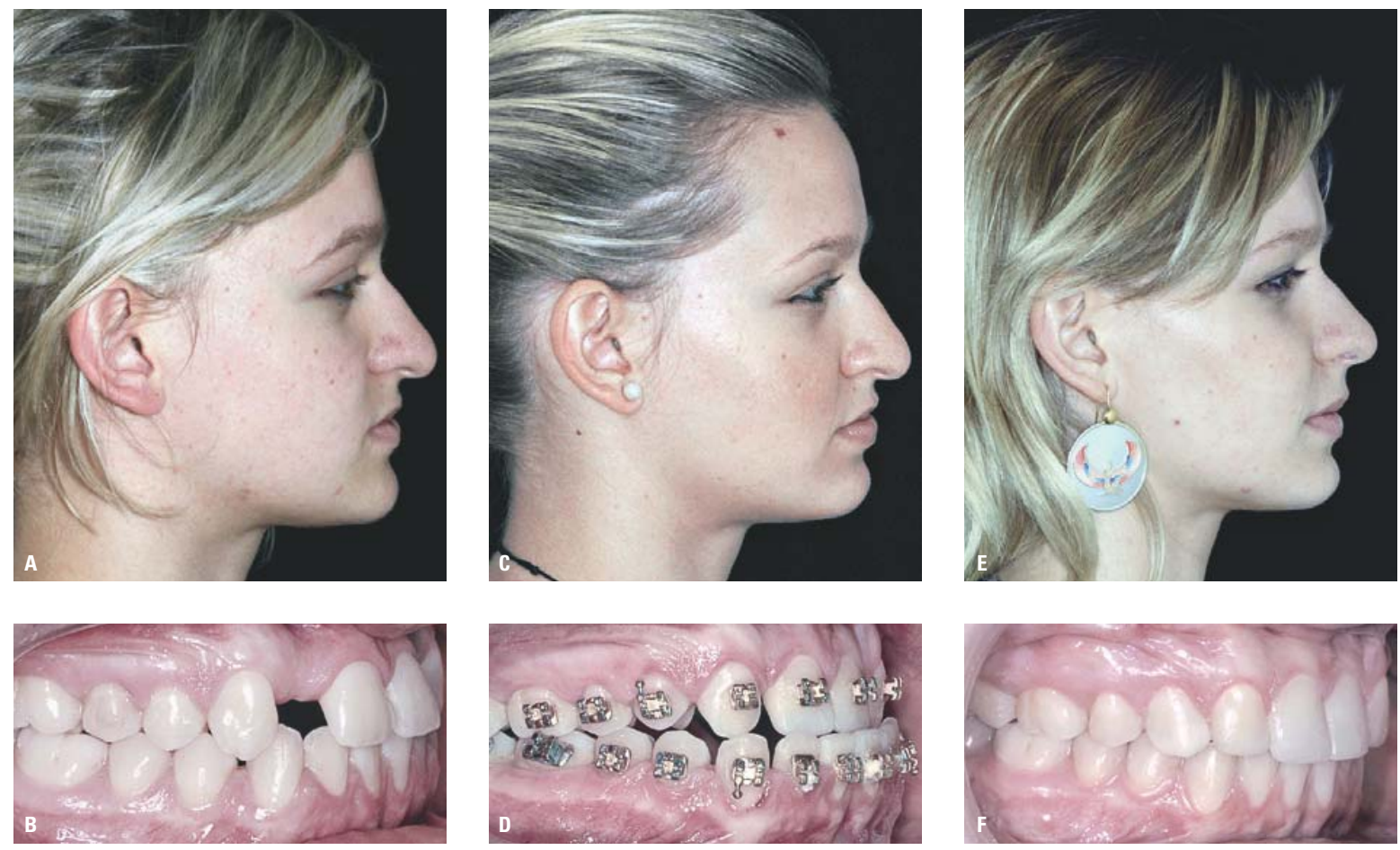

FIGURA 4 - Caso LM: a paciente não estava satisfeita após o tratamento ortodôntico para reabertura do espaço, realizado por outro ortodontista (A, B). Durante o segundo tratamento ortodôntico, após o fechamento do espaço, o perfil não foi alterado, apesar da inclinação significante dos incisivos superiores (C, D). No final do tratamento, o trespasse horizontal foi corrigido cirurgicamente e o perfil aprimorado (E, F). 

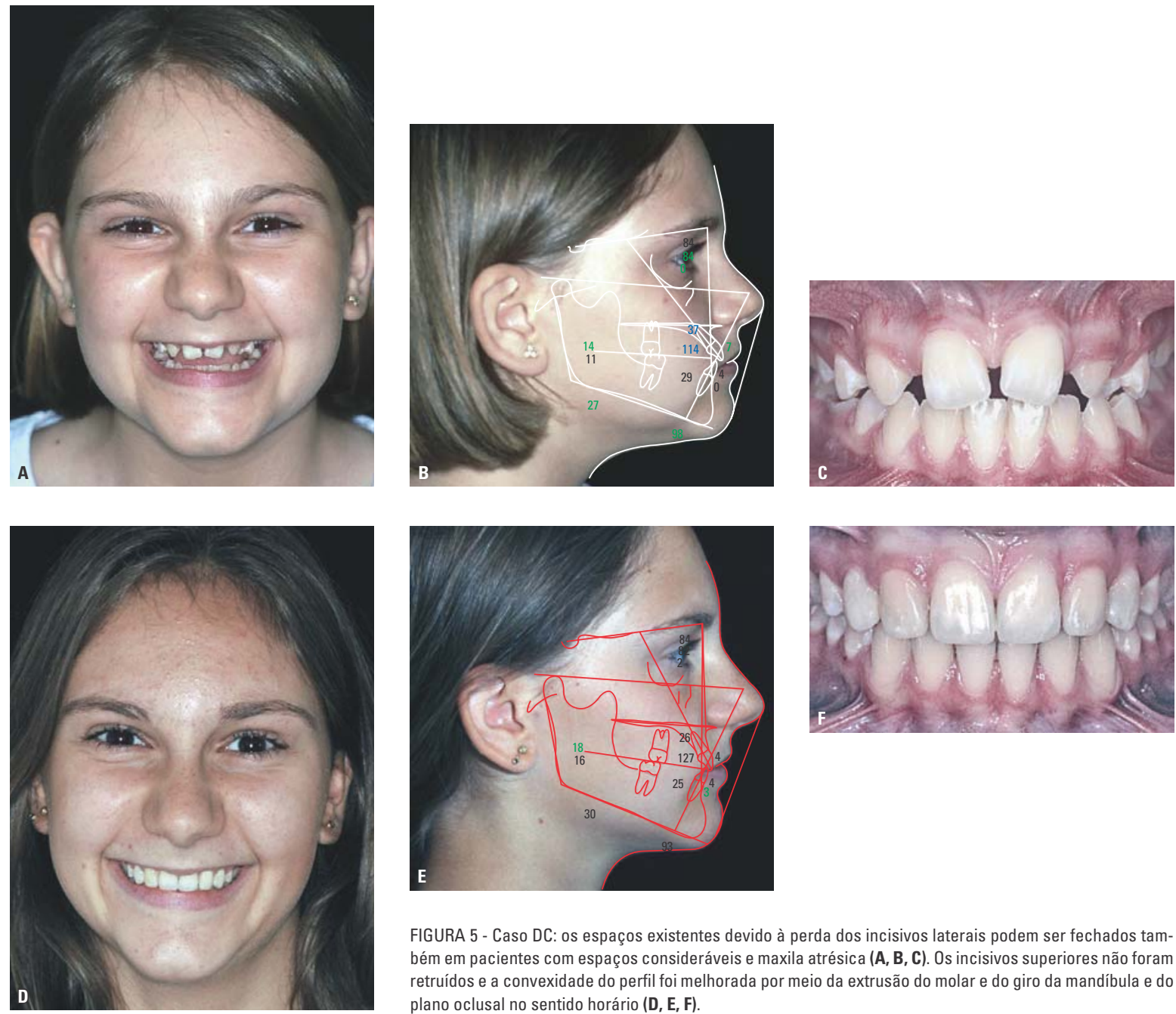

FIGURA 5 - Caso DC: os espaços existentes devido à perda dos incisivos laterais podem ser fechados também em pacientes com espaços consideráveis e maxila atrésica (A, B, C). Os incisivos superiores não foram retruídos e a convexidade do perfil foi melhorada por meio da extrusão do molar e do giro da mandíbula e do plano oclusal no sentido horário (D, E, F).

perfil, aumentando a altura da face através da extrusão posterior (Fig. 5). Nos pacientes hiperdivergentes, o fechamento do espaço é, freqüentemente, a melhor solução, em casos de sorriso gengival, nos pacientes cirúrgicos ou quando um tratamento com extração ortodôntica é a melhor solução.

O Sr. tem grande experiência com tratamentos precoces. Conte-nos sobre sua teoria de movimentar os dentes permanentes sem, necessariamente, tocá-los, apenas trabaIhando nos dentes decíduos? Lincoln Nojima

$\mathrm{Na}$ dentadura mista, pode-se corrigir muitas más oclusões com ancoragem nos dentes decíduos (Fig. 6), em vez de nos dentes permanentes $4,5,6,8-11$.

A melhor época para começar o tratamento ativo é o primeiro período transitório, pois os molares e caninos decíduos podem sustentar bem 

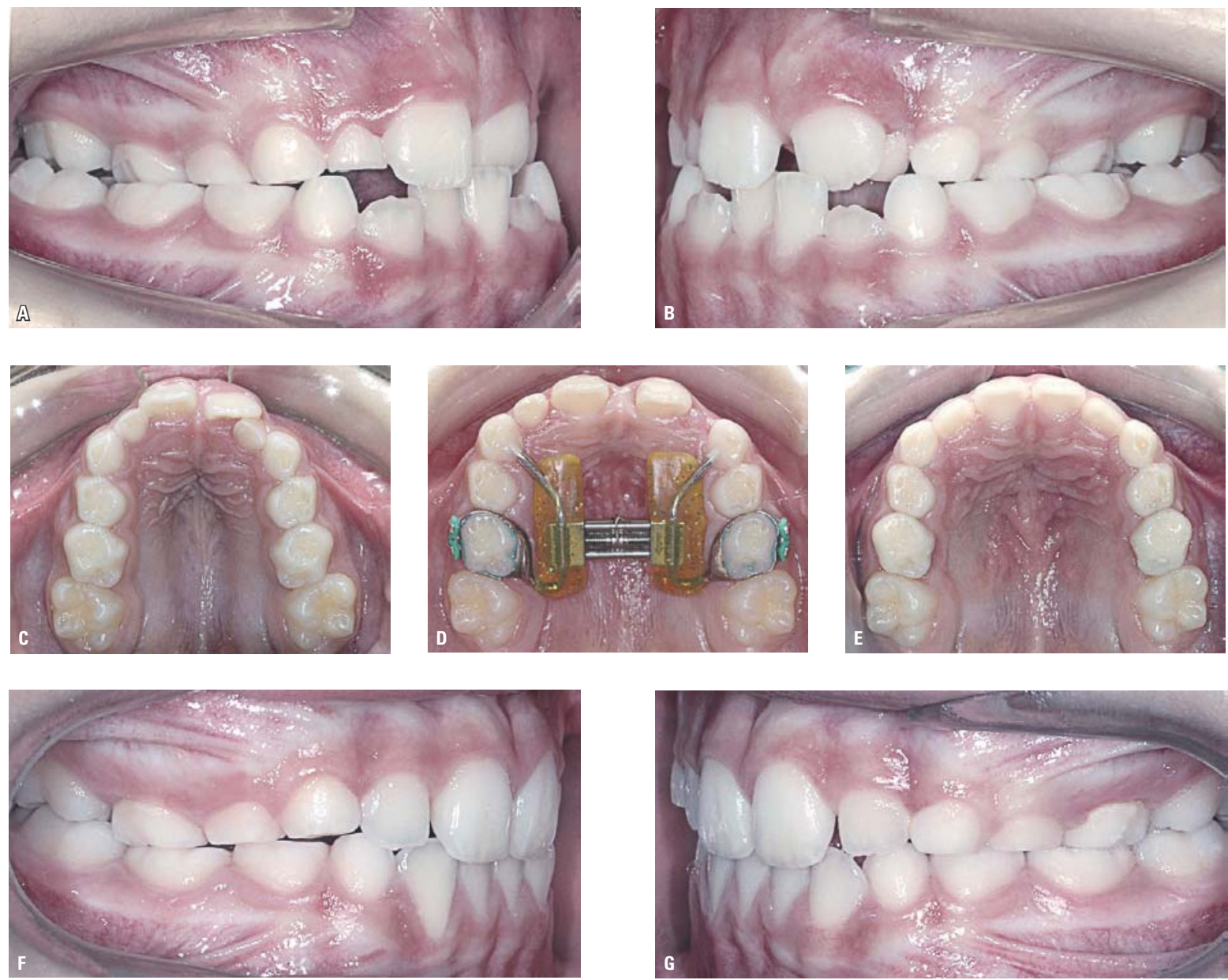

FIGURA 6 - Caso AP: a mordida cruzada nos molares permanentes e nos incisivos centrais (A, B, C) foi corrigida com a expansão rápida da maxila ancorada sobre dentes decíduos (D), sem cooperação e sem tocar os dentes permanentes (E, F, G).
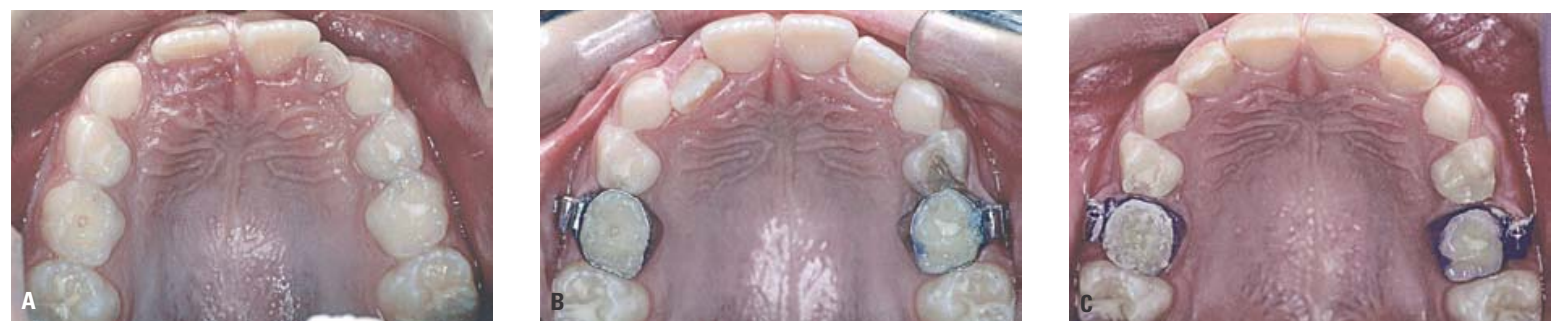

FIGURA 7 - Caso CL: o arco superior foi expandido (A, B) e o alinhamento do incisivo superior foi obtido sem tocar os dentes permanentes e com certa cooperação (C). 

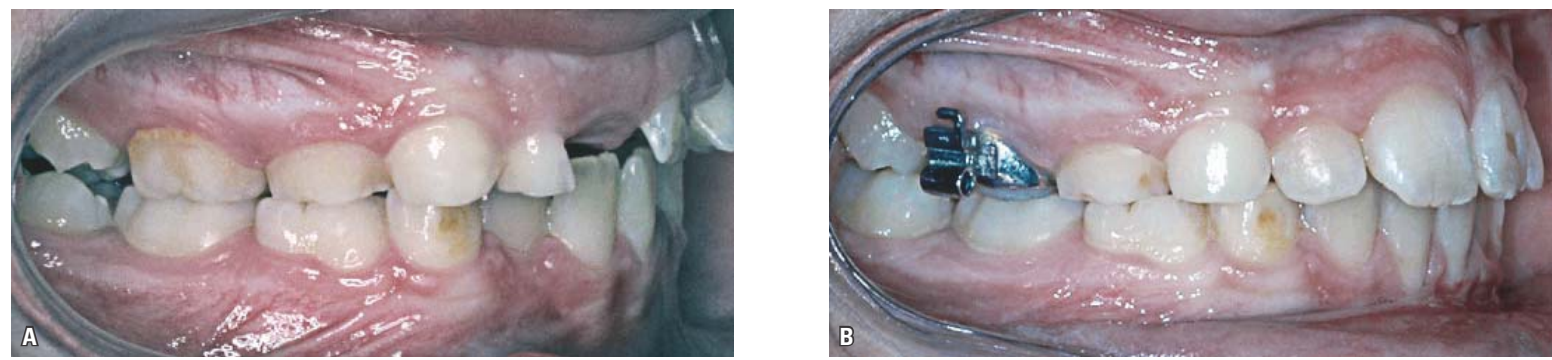

FIGURA 8 - Caso MO: a relação Classe II (A) foi corrigida também nos molares permanentes (B), com aparelhos aplicados nos molares decíduos e com certa cooperação.

aparelhos fixos, assim como forças ortodônticas e ortopédicas. Os molares e incisivos permanentes se movem espontaneamente e se auto-corrigem, mesmo se já irrompidos. Os contatos oclusais e o momento exato, utilizando o procedimento correto, guiarão os dentes permanentes, proporcionando uma boa, ou significantemente melhor, intercuspidação.

Durante o segundo período transitório, procedimentos clínicos simples, com pouca necessidade de cooperação, guiarão a erupção dos pré-molares e caninos.

Esse método clínico pode ser usado, não apenas nas indicações clássicas do tratamento precoce (mordida cruzada [Fig. 6, 7], desvio funcional da mandíbula e discrepâncias verticais), mas, também, em alguns problemas de Classe II (Fig. 8), III ou I e assimetrias.

Com isto, estaremos prevenindo iatrogenias nos dentes permanentes, que não foram tocados, e tratamentos longos com aparelhos fixos em dentes permanentes, pois a segunda fase do tratamento é significativamente mais curta, quando comparada ao tratamento em uma fase.

Dessa forma, também, obtêm-se melhores resultados, pois não há compensação dentoalveolar nos molares e incisivos permanentes, com nenhuma ou mínima cooperação por parte do paciente.

Assim, o tratamento se torna muito mais eficiente, com melhor relação custo-benefício, pois há auto-correção dos dentes permanentes, sem a utilização de qualquer biomecânica sofisticada, com mínimo tempo de cadeira e um custo reduzido.

No próximo mês de outubro, o Sr. estará visitando o Rio de Janeiro, para celebrarmos os 50 anos do primeiro curso de Ortodontia do Brasil. Nosso convite foi baseado em sua excelência no diagnóstico e no planejamento da terapia ortodôntica. O que gostaria de contar aos jovens ortodontistas brasileiros a respeito de sua filosofia? Lincoln Nojima

É um privilégio ser convidado e será uma grande honra estar nessa celebração histórica.

O tópico de meu curso é limitado ao tratamento precoce, mas a mensagem que eu tentarei passar ao ortodontista jovem é ampla.

Hoje em dia, um século após Angle, e depois de poucas décadas de evidência científica, parece que os tópicos mais atrativos para ortodontistas são as novas tecnologias, os novos produtos, os novos métodos para evitar extrações, para fazer crescer osso e alongar mandíbulas. Eu acredito que, agora, é tempo, também, de começar uma nova discussão sobre os tópicos mais relevantes na Ortodontia: diagnóstico, objetivos do tratamento, predição de crescimento e plano de tratamento. Deve-se ter como objetivo maior não apenas eficiência e efetividade nos procedimentos ortodônticos, mas, também, evitar tratamentos prolongados e seus efeitos iatrogênicos. 


\section{REFERÊNCIAS}

1. BELSER, U. C.; BUSER, D.; HESS, D.; SCHMID, B.; BERNARD J. P.; LANG, N. P. Aesthetic implant restorations in partially edentulous patients: a critical appraisal. Periodontology 2000 Copenhagen, v. 17, p. 132-150, 1998

2. BERNARD, J. P.; SCHATZ, J. P.; CHRISTOU, P.; BELSER, U.; KILIARIDIS, S. Long-term vertical changes of the anterior maxillary teeth adjacent to single implants in young and mature adults: a retrospective study. J. Clin. Periodontol., Copenhagen, v. 31, p. 1024-1028, 2004

3. CHANG, M.; WENNSTRÖM, J. L.; ODMAN, P.; ANDERSSON, B. Implant supported single-tooth replacements compared to contralateral natural-teeth-crown and soft tissue dimensions. Clin. Oral Impl. Res., Copenhagen, v. 10, p. 185-194, 1999.

4. COZZANI, M.; COZZANI, P.; ROSA, M.; SICILIANI, G. Deciduous dentition-anchored rapid maxillary expansion in crossbite and non-crossbite mixed dentition patients: reaction of the permanent first molar. Progr. Orthod., Berlin, v. 4, p. 15-22, 2003.

5. COZZANI, M.; MIRENGHI, S.; GUIDUCCI, A.; MANFRINA, M.; ROSA, M.; SICILIANI, G. Rapid maxillary expansion in mixed dentition: permanent maxillary incisor behavior, a long term study. Progr. Orthod., Berlin, v. 4, no. 2, p. 105, 2003.

6. COZZANI, P.; ROSA, M.; COZZANI, M. Spontaneous permanent molar expansion in crossbite and non-crossbite patients. Eur. J. Orthod., Oxford, v. 21, no. 4, p. 434, 1999.

7. NORDQUIST, G. G.; McNEILL, R. W. Orthodontic vs. restorative treatment of the congenitally absent lateral incisor: long term periodontal and occlusal evaluation. J. Periodontol., Chicago, v. 46, p. $139-143,1975$
8. ROSA, M. An interview on early treatment. Progr. Orthod. Berlin, v. 7, no. 2, p. 66-77, 2006.

9. ROSA, M. Espansione dell'arcata superiore in dentatura mista senza collaborazione e senza toccare i denti permanenti: indicazioni e timing. Ortognatodonzia Italiana, Milão, v. 13, no. 1, p. 33-43, 2006.

10. ROSA, M. Sequential slicing of deciduous teeth. J. Clin. Orthod., Boulder, v. 35, no. 11, p. 696-701, 2001.

11. ROSA, M. Tratamiento precoz del apiñamiento dental en dentición mixta: procedimientos de intervención no habituales sin tocar los dientes permanentes. Rev. Esp. Orthod., Madrid, v. 33, p. 203-214, 2003.

12. ROSA, M.; ZACHRISSON, B. U. Integração da Ortodontia: fechamento de espaço e da Odontologia estética no tratamento de pacientes com agenesia de incisivos laterais superiores. Rev. Clin. Ortodon. Dental Press, Maringá, v. 1, n. 1, p. 41-55, fev./mar. 2002

13. ROSA, M.; ZACHRISSON, B. U. Integrating esthetic dentistry and space closure in patients with missing maxillary lateral incisors: further improvements. J. Clin. Orthod., Boulder, v. 51, no. 9, p. 563-573, 2007

14. ROSA, M.; ZACHRISSON, B. U. Integrating esthetic dentistry and space closure in patients with missing maxillary lateral incisors. J. Clin. Orthod., Boulder, v. 35, no. 4, p. 221-234, Apr. 2001.

15. THILANDER, B.; ÖDMAN, J.; LEKHOLM, U. Orthodontic aspects of the use of oral implants in adolescents: a 10-year follow-up study. Eur. J. Orthod., Oxford, v. 23, no. 6 p. 715-731, Dec. 2001

\section{Adilson Luiz Ramos}

- Professor adjunto do departamento de Ortodontia da Universidade Estadual de Maringá - UEM.

- Coordenador do programa de pós-graduação em Odontologia da UEM.

- Professor dos cursos de especialização em Ortodontia da UEM, CESUMAR e AMO-Dental Press.

- Editor da Revista Dental Press de Ortodontia e Ortopedia Facial (2003 a 2006).

\section{David Normando}

- Professor da Disciplina de Ortodontia da UFPa.

- Coordenador do Curso de Especialização em Ortodontia da ABO-Pa.

- Doutorando em Odontologia-Ortodontia, pela UERJ.

- Mestre em Clínica Integrada pela USP.

- Especialista em Ortodontia pela PROFIS-USP/Bauru.

\section{Lincoln Nojima}

- Mestre e Doutor em Odontologia (Ortodontia) - UFRJ.

- Professor Adjunto de Ortodontia - UFRJ.

- Coordenador do Programa de Pós-Graduação em Odontologia - UFRJ.

- Diplomado pelo Board Brasileiro de Ortodontia e Ortopedia Facial.

\section{Marcos Alan Vieira Bittencourt}

- Mestre e Doutor em Ortodontia pela UFRJ.

- Especialista em Radiologia pela UFBA.

- Professor Adjunto de Ortodontia da UFBA.

- Diplomado pelo Board Brasileiro de Ortodontia e

Ortopedia Facial. 